\title{
IMAGE FUSION APPLIED TO SATELLITE IMAGERY FOR THE IMPROVED MAPPING AND MONITORING OF CORAL REEFS: A PROPOSAL
}

\author{
M. Gholoum ${ }^{\text {a }}$, D. Bruce ${ }^{\mathrm{a}}$, S. Al Hazeam ${ }^{\mathrm{b}}$ \\ ${ }^{\text {a }}$ School of Natural and Built Environments, Barbara Hardy Institute, University of South Australia, GPO Box 2471, \\ Adelaide, SA, 5001, Australia - (ghomm001, David.Bruce)@unisa.edu.au \\ ${ }^{\mathrm{b}}$ Aquaculture, Fisheries and Marine Environmental Department, Kuwait Institute for Scientific Research, P O Box: \\ 1638, 22017 Al-Salmyah, Kuwait - shazeem@kisr.edu.kw \\ Commission III, WG III/3
}

KEY WORDS: Image Fusion, Coral Reef, Hyperion, WorldView 2, Environmental Management, Image Classification

\begin{abstract}
A coral reef ecosystem, one of the most complex marine environmental systems on the planet, is defined as biologically diverse and immense. It plays an important role in maintaining a vast biological diversity for future generations and functions as an essential spawning, nursery, breeding and feeding ground for many kinds of marine species. In addition, coral reef ecosystems provide valuable benefits such as fisheries, ecological goods and services and recreational activities to many communities. However, this valuable resource is highly threatened by a number of environmental changes and anthropogenic impacts that can lead to reduced coral growth and production, mass coral mortality and loss of coral diversity. With the growth of these threats on coral reef ecosystems, there is a strong management need for mapping and monitoring of coral reef ecosystems. Remote sensing technology can be a valuable tool for mapping and monitoring of these ecosystems. However, the diversity and complexity of coral reef ecosystems, the resolution capabilities of satellite sensors and the low reflectivity of shallow water increases the difficulties to identify and classify its features.
\end{abstract}

This paper reviews the methods used in mapping and monitoring coral reef ecosystems. In addition, this paper proposes improved methods for mapping and monitoring coral reef ecosystems based on image fusion techniques. This image fusion techniques will be applied to satellite images exhibiting high spatial and low to medium spectral resolution with images exhibiting low spatial and high spectral resolution. Furthermore, a new method will be developed to fuse hyperspectral imagery with multispectral imagery. The fused image will have a large number of spectral bands and it will have all pairs of corresponding spatial objects. This will potentially help to accurately classify the image data. Accuracy assessment use ground truth will be performed for the selected methods to determine the quality of the information derived from image classification. The research will be applied to the Kuwait's southern coral reefs: Kubbar and Um Al-Maradim.

\section{REVIEW OF PREVIOUS METHODS}

A Coral Reef Ecosystem (CRE) is one of the most complex environmental systems on the planet, and is defined as biologically diverse and immense (Connell, 1978; Porter and Tougas, 2001). This ecosystem has been called the rainforest of the marine world as it is home to many known marine species (Bryant et al, 1998). Coral reefs are important ecosystems to many people around the world (Moberg and Folke, 1999; Nurlidiasari, 2004). They play an important role in maintaining a vast biological diversity and genetic library for future generations (Moberg and Folke, 1999). They function as essential spawning, nursery, breeding and feeding ground for many kinds of marine species such as fish, marine turtles, worms, molluscs, crustaceans and sponges (Moberg and Folke, 1999). CRE provides valuable benefits, particularly to local communities who depend on these resources for their livelihood (Nurlidiasari, 2004). Moreover, CRE serves as physical and natural barriers for oceanic currents and waves, protecting coastlines from erosion and creating suitable environments for other ecosystems such as mangroves and seagrass beds (Moberg and Folke, 1999; UNEP, 2006).

This valuable resource, however, is highly threatened by a number of environmental changes and anthropogenic impacts such as natural disturbances, overfishing, pollution and tourism (Johannes and Riepen, 1995; Moberg and Folke, 1999). These impacts can lead to reduced coral growth and production, mass coral mortality and loss of coral diversity (Eghtesadi-Araghi, 2011).

Information on the health of coral reef ecosystem status is essential for conservation and sustainable utilization. Currently, there is a limited knowledge on the condition and community assemblage composition of coral reef ecosystems (Knowlton and Jackson, 2008). With the growing threats of climate change, natural phenomena and anthropogenic impacts on CRE, there is a strong management need for the more accurate mapping and monitoring of these systems (Dekker et al, 2001).

In the past three decades, researchers have witnessed rapid development of advanced sensors and data processing methodologies in order to advance the understanding of Earth's environment, specifically coral reef ecosystem (Mumby and Edwards, 2002; Andréfouët et al, 2003; Eakin et al, 2010).

Remote sensing technology, such as airborne and satellite sensors, can potentially provide more accurate classification of coral reef ecosystem, in a shorter period of time and in a more cost effective manner than via in situ surveys (Eakin et al, 2010). Airborne hyperspectral sensors have been used to uniquely identify and map coral reef ecosystems (Clark et al, 1997; Mumby et al, 1998). They have the advantage over data from satellite sensors because the user has influence on the mission in terms of time schedules, calibration measurements, flight line arrangements, spectral and spatial resolutions, and selecting acceptable weather conditions (Cetin, 2004). Mumby 
et al (1998) used CASI (Compact Airborne Spectrographic Imager) for mapping coral reefs habitats of the Turks and Caicos Islands (British West Indies). The study suggested that CASI is capable of mapping benthic habitat classes with a high level of accuracy. However, airborne hyperspectral data is not commonly used due to the large expense involved in acquiring such information (Holden \& LeDrew, 1998).

Many satellite sensors have also been recognized as useful tool to monitor and map CRE. Satellite sensors cover large geographic areas and have good temporal coverage in most areas of interest (Dekker et al, 2001). This can enhance the understanding of coral reef ecosystems and their threats, by providing spatio-temporal data on reef ecosystems and the environmental conditions influencing them (Eakin et al, 2010). NASA has developed a baseline of global reef maps that can be a foundation for future more detailed scientific investigation (NASA, 2011a).

The common multispectral sensors like those on Landsat, SPOT, IKONOS, QuickBird and WorldView 2 have been used in mapping and monitoring coral reef ecosystems for some time (Mumby et al, 1997; Mumby and Edwards, 2002; Fonseca et al, 2010; Kerr, 2010). However, the accuracy of identifying coral reef features has been limited due to the spectral and spatial resolutions of these sensors.

The development of Hyperspectral sensors has improved the multispectral capabilities by dealing with narrow spectral bands over a contiguous spectral range (Chang, 2003). Increasing number of bands has increased the number of coral reef substrate classes that can be discriminated (Kutser et al, 2006). For example, Kutser et al (2006) investigated the suitability of the Hyperion satellite sensor for mapping coral reef benthic substrates in Cairns reef, in the northern section of the Australian Great Barrier Reef (GBR). The results suggested the capability of Hyperspectral data to discriminate and map bottom type and water depth. However, the spatial resolution of satellite based Hyperspectral sensors remains an issue to be solved in the future (Cetin, 2004).

Monitoring the changes in coral reef ecosystem using remote sensing data can be a cost effective and time efficient of coral reef management (Mumby et al, 1999; Maeder et al, 2002). A number of researchers used time-serious data to detect changes in overall reflectance that can be attributed to major changes in coral reef ecosystems using remote sensing techniques (Andréfouët et al, 2001; Dustan et al, 2001; Palandro et al, 2003; Sterckx et al, 2005; Scopélitis et al, 2010). However, the spectral and spatial resolutions of the multiple temporal imageries can be limiting factors in the application of the method. In addition, the temporal texture associated with areas of CRE degradation can be highly variable.

Therefore, the adequacy and accuracy of remote identification for mapping and monitoring coral reefs ecosystems remains unclear due to technical constraints. Thus, the actual challenge is to achieve both high spectral and high spatial resolutions in order to have more accurate image data to discriminate coral reef ecosystems whilst still maintaining the benefits accruing from the use of operational spaceborne systems.

\section{IMAGE FUSION AND LIMITATIONS}

In many applications of remote sensing, such as in coral reef ecosystem mapping, images with high accuracy both spectrally and spatially are required (Kutser et al, 2006; Eakin el at, 2010).
To achieve this outcome, image fusion methods, or pansharping, can potentially efficiently and accurately provide images with high spectral and high spatial resolutions (Zhang, 2008). There are few research studies undertaken on mapping and monitoring coral reef ecosystems using image fusion techniques. Hanaizumi et al (2008) used the pan-sharping method based on multiple regression analysis to enhance satellite imagery from FORMOSAT-2 at Ishigaki and Ryukyu coral reef ecosystems in Japan. The pan-sharping method was implemented pixel-by-pixel and incorporated the panchromatic information without distorting the original spectral information. The brightness components of each lower spatial resolution multispectral band were replaced with higher spatial resolution values derived from the panchromatic band. The spatial resolution of the multispectral band was improved from $8 \times 8 \mathrm{~m}$ to $2 \times 2 \mathrm{~m}$ and the method produced a visual improvement to coral reef imagery.

Ninsawat and Tripathi (2003) used the Intensity-Hue-Saturation (IHS) method to merge multispectral data from LISS-III $(23.5 \mathrm{~m})$ with the panchromatic data $(5.8 \mathrm{~m})$ from the same satellite (Indian Remote Sensing satellite IRS-1D), to generate multispectral and higher spatial resolution image data of Phi Phi Island, Thailand. The study was aimed to map coral reef ecosystems and to identify the spectral distinction between healthy and dead coral. The fused image and depth invariant index based on classified field data generated a classification of coral reef ecosystem type image without any unclassified pixel. The study confirmed the capability of (IHS) method to provide better description of coral reef ecosystem; thereby the coral reef ecosystem can be more accurately classified.

In this study it is proposed to utilize MS imagery from WorldView 2 (2m spatial resolution) and hyperspectral imagery from Hyperion $(30 \mathrm{~m}$ spatial resolution). The spectral correspondence between these sensors is shown in table 1 .

Table1: Spectral Correspondence between Hyperion and WorldView 2 sensors

\begin{tabular}{|l|l|l|l|}
\hline $\begin{array}{l}\text { WV2 } \\
\text { MS } \\
\text { Band } \\
\text { No. }\end{array}$ & $\begin{array}{l}\text { Wavelength } \\
(\mathrm{nm})\end{array}$ & $\begin{array}{l}\text { Hyperion } \\
\text { Bands }\end{array}$ & $\begin{array}{l}\text { No of } \\
\text { Hyperion } \\
\text { bands }\end{array}$ \\
\hline 1 & $400-450$ & $5-10$ & 6 \\
\hline 2 & $450-510$ & $11-16$ & 6 \\
\hline 3 & $510-580$ & $17-23$ & 7 \\
\hline 4 & $585-625$ & $24-27$ & 4 \\
\hline
\end{tabular}

However, the pan-sharpening process of the Hyperspectral bands (30m) with the first four Multispectral bands of WorldView2 imagery $(2 \mathrm{~m})$ is potentially problematic due to the extreme 15:1 ratio of spatial resolutions. In addition the large number of Hyperspectral bands corresponding to each WV2 MS band (Table 1) might not allow fusion methods to be easily applied (Garzelli et al, 2010). The outcome of applying standard pan-sharpening methods may contain artifacts that reduce the quality of the fused product. However, Ling et al (2006) suggest that even with spatial resolution ratios between 10:1 and 30:1, the fused image still presents information which is more interpretable than the original image. Whilst standard methods will be applied, this study will develop a specific fusion model to as best as possible preserve the spectral and spatial information of the input images (see 3.5). 
3.

RESEARCH PLAN

The chart in Appendix.1 describes the structure of the proposed research.

\subsection{Site Selection}

The site selected for this study is Kuwait southern CRE (Kubbar and Umm Al-Maradem) (Figure 1). The site is selected based on a number of criteria. In comparison with other CRE around the world, the selected site represents an extreme environmental condition due to excessive human activities and natural environmental impacts (Kuwait Diving Team (KDT), 2009). In addition, there are few scientific studies implemented in or near the selected site. This has led to a limited understanding by experts and policy makers of Kuwait's CRE and how these are changing over time. The location of the selected site, in the southern area of Kuwait, allows the site to be accessible to public, as it is far away from politically restricted areas, which are mainly located in northern part of Kuwait. The availability and the cost of resources (field measurement equipment, data from Al-Hazeem (2007) and satellite imagery) are considered as a secondary site selection criteria. On these counts the selected site scores well against other candidate CRE.

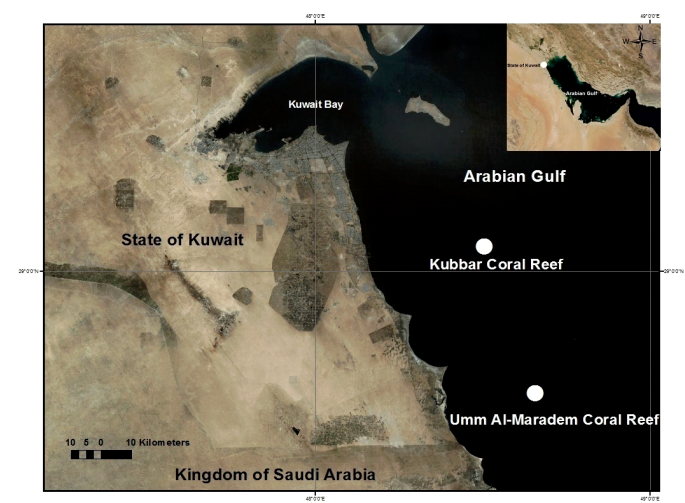

Figure 1: Map Showing the Location of the Selected Kuwait's Coral Reef (Kubbar and Umm Al-Maradem (ESRI, 2011)

\subsection{Image Selection}

From table 2, it can be concluded that Worldview-2 could be a suitable satellite high spatial resolution sensor for this study as it has the highest spatial resolution. On the other hand, Hyperion could be a most suitable satellite sensor as it has the highest spectral resolution.

Table 2: Comparison of Satellite Images Spectral, Spatial, Temporal Resolutions and Spectral Range

\begin{tabular}{|c|c|c|c|c|}
\hline Satellite & $\begin{array}{l}\text { No. of Spectral } \\
\text { Bands }\end{array}$ & $\begin{array}{l}\text { Spatial } \\
\text { Resolution (m) }\end{array}$ & $\begin{array}{l}\text { Temporal } \\
\text { Resolution } \\
\text { (Days) }\end{array}$ & \begin{tabular}{|l|} 
Spectral \\
Range $(\mu \mathrm{m})$
\end{tabular} \\
\hline \begin{tabular}{|l|}
${ }^{1}$ Landsat 4 MSS \\
${ }^{2}$ Landsat 5 TM
\end{tabular} & \begin{tabular}{|l|}
4 \\
7
\end{tabular} & $\frac{80}{30}$ & $\frac{16}{16}$ & \begin{tabular}{|l|}
$0.5-12.6$ \\
$0.45-12.5$
\end{tabular} \\
\hline $\begin{array}{l}{ }^{3} \text { Landsat } 7 \\
\text { ETM+ }\end{array}$ & 7 & $\begin{array}{l}15 \text { panchromatic } \\
30 \text { multispectral }\end{array}$ & 16 & $0.45-12.5$ \\
\hline \begin{tabular}{|l}
${ }^{4}{ }^{4}$ MODIS' (Aqua) $^{\prime}$ \\
\end{tabular} & 36 & $250 m-1000$ & & $0.4-13$ \\
\hline${ }^{5}$ Ikonos & 4 & $\begin{array}{l}0.8 \\
\text { panchromatic } \\
4- \\
\text { multispectral }\end{array}$ & $\begin{array}{l}\text { Approximately } 3 \\
\text { days }\end{array}$ & $0.526-0.929$ \\
\hline${ }^{6}$ SPOT 5 & 4 & $\begin{array}{l}22.5-5 \mathrm{~m} \\
\text { panchromatic } \\
10 \mathrm{~m} \\
\text { Multispectral }\end{array}$ & $2-3$ & $0.48-1.75$ \\
\hline \begin{tabular}{|l}
${ }^{7}$ Hyperion \\
${ }^{8}$ WorldView 2
\end{tabular} & \begin{tabular}{|l|}
220 \\
8
\end{tabular} & $\begin{array}{l}30 \\
1.85 \text { Multispectral } \\
0.50 \text { Panchromatic }\end{array}$ & $\begin{array}{l}16 \\
1.1\end{array}$ & \begin{tabular}{|l|}
$0.4-2.5$ \\
$0.4-1.04$ \\
\end{tabular} \\
\hline \multicolumn{5}{|l|}{$\begin{array}{l}\text { 1-NASA, n.d } \\
\text { 2- NASA, nd. } \\
\text { 3-NASA, } 1999 \\
\text { 4-NASA, 2011b } \\
\text { 5-GeoEye, 2011 } \\
\text { 6-GIC, } 2010 \\
\text { 7-USGS, } 2010 \\
\text { 8- DigitalGlobe 2 }\end{array}$} \\
\hline
\end{tabular}

\subsection{Geometric and Radiometric Corrections}

Selected images will be geometrically corrected using a number of techniques, such as pointwise polynomial, piecewise polynomial and orthorectification correction models. In addition, the study will conduct a radiometric correction for the selected images to remove the atmospheric and water column effects. Atmospheric correction methods, such as Moderate Resolution Atmospheric Transmittance (MODTRAN) and Atmospheric and Topographic Correction Model (ATCOR), will be employed to remove atmospheric attenuation and scattering. Approximate water column correction methods, such as those utilized by Lyzenga (1978) and Lee et al (1999), will be used to remove the effects of water column attenuation, improve the visual interpretation of imagery and improve classification accuracy. Furthermore, the spectral reflection of light from water surface (sun glint) will be removed using various techniques. For example, Hochberg et al (2003) presented a new method wherein sun glint component of the remotely sensed signal is removed from visual wavelength spectral bands by the utilization of information from a spectral band in near-infrared (NIR). Image pixels are adjusted to remove the glint component of the recorded signal, leaving only the component derived from benthic reflectance and radiative transfer processes within the water column. These techniques will potentially demonstrate a substantial visual improvement in the shallow coral reef ecosystem images, thereby increasing accuracy and classification.

\subsection{Image Classification}

Prior to implementing image fusion process, the selected images will be simply classified using a number of pixel-based digital image classification methods (supervised and unsupervised classification) such as the Migrating Means Clustering classifier (MMC) and the maximum likelihood classifier. This will be followed by more complex classification method such as objectoriented classification (OOC).

\subsection{Image Fusion}

After the selected images are classified into object classes, a number of image fusion methods such PCA (Principal Components Analysis), arithmetic combinations, and wavelet based fusion will be examined to fuse the high spectral resolution and low spatial resolution image with the low spectral resolution and high spatial resolution image. The main objective of the fusion methods will be to create from the collection of input images a single output image which contains a better description of the scene that the one provided by any of the individual input images (Mitchell, 2010).

In addition, a specific fusion model will be developed and tested to preserve the spectral information of the image. The new developed method will fuse hyperspectral imagery (possibly Hyperion) with multispectral imagery (possibly Worldview 2). When fusing these two images, each band of the high spatial resolution image (e.g., Coastal Blue band (400-450 nm) of Worldview 2) will be merged with the multiple spectral of the high spectral resolution image (e.g. 6 bands between 400-450 $\mathrm{nm}$ of Hyperion). The fused image will have a large number of spectral bands and this will potentially provide more useful and accurate information. In addition, a new fusion method will be developed to combine information from different sources based at the object level. The method will produce all pairs of 
corresponding spatial objects (Peng et al, 2010). When fusing the two selected images, pairs of objects will be identified (one object from each image), and objects in each pair will be fused into a single object (Peng et al, 2010). This single fused object will have pair of objects that represent the same entity and same location (Peng et al, 2010). The spatial attributes of these objects will describe the location, appearance characteristic, shape and topology of an entity (Peng et al, 2010). The large number of image objects will help to accurately classify the image data.

\subsection{Image Classification (Fused Images)}

The next step will be classifying the fused images into different classes using the same previous classification methods; objectoriented classification (OOC), maximum likelihood classifier (MLC) and migrating Means Clustering classifier (MMC). The classes of the fused images will be superimposed in a GIS layers into different maps for further analysis.

\subsection{Accuracy Assessment}

Accuracy assessment will be performed for the selected algorithms at selected sites (Kubbar and Umm Al-Maradem CRE) based on field work data. It will help determining the quality of the information derived from image classification and it will be used as a comparative tool between various algorithms and techniques to test which is the best. Accuracy control points (ACPs) will be distributed utilizing a stratified random sampling methodology around the two southern coral reefs (Kubbar and Umm Al-Maradem). The ACPs will be similar to those ACPs of pervious study done by Al-Hazeem (2007). However, this study may require additional ACPs in order to obtain a more reliable result.

\section{REFERENCES}

Al-Hazeem, S 2007, An ecological study of the coral reefs of Kuwait islands, School of Ocean Sciences, University of Wales, Bangor, (Thesis for degree of Doctor of Philosophy)

Andrefouet, S, Kramer P, Torres-Pulliza, D, Joyce, K E, Hochberg, E J, Garza-Pérez, R, et al 2003, Multi-site evaluation of IKONOS data for classification of tropical coral reef environments, Remote Sensing of Environment, vol. 88, pp. 128-143

Andrefouet, S, Muller-Karger, F, Hochberg, E, Hu, C \& Carder, K 2001, Change detection in shallow coral reef environments using Landsat $7 \mathrm{ETM}+$ data, Remote Sensing of Environment, vol. 79, pp. 150-162

Bryant, D, Burke, L, Mcmanus, J\& Spalding, M 1998, Reef At Risk: A Map-Based Indicator of Threats to the World's Coral Reefs, World Resources Institute, Washington

Cetin, H 2004, Comparison of spaceborne and airborne hyperspectral imaging systems for environmental mapping, Proceedings of Commission VII, XXthISPRS Congress Istanbul, Turkey

Chang, C 2003, Hyperspectral Imaging: Techniques for Spectral Detection and Classification, Kluwer Academic/Plenum Publishers, New York

Clarke, C., Ripley, H., Green, E., Edwards, A. \& Mumby, P, 1997, Mapping and measurement of tropical coastal environments with hyperspectral and high spatial resolution data, International Journal of Remote Sensing, 18, 237- 42.

Connell, J H 1978, Diversity in tropical rain forests and coral reefs, Science (199) 1302-1310

\subsection{Coral Reef Monitoring}

Additionally, time and resources permitting, two sets of images of the test site with different dates will be compared to determine the quality of the information derived from image classification and to detect the changes in coral reef ecosystem over time

The same processes of image calibration and classification established previously in the image processing analysis will be applied to the second image of the test site. GIS analysis of the change between the two dates will reveal if significant change has occurred. However, this process will be only undertaken if the developed fusion method was successful and sufficient time and funds persist.

\section{CONCLUSION}

This research study will potentially contribute to the body of knowledge by providing researchers and decision makers with a tool to identify and map coral reef features in more detail. The resolution limitations of current satellite sensors in mapping coral reef ecosystem can be overcome by using improved image fusion techniques. This will potentially provide more accurate information on the current condition and community assemblage of CRE to marine decision makers, leading to better management, conservation and sustainable utilization of these marine resources. In addition, if the developed methods are successful, they can be applied to other CREs around the World due to the operational nature and near global coverage available from Low Earth Orbit (LEO) remote sensing satellites.

Dekker, G A, Brando, E V, Anstee, M J, Pinnel, N, Kutser, T, Hoogenboom, J E, Peters, S, Pasterkamp, R, VOS, R, Olbert, C\& Malthus, J M T 2001, Imaging Spectrometry: Basic Principles Applications: Imaging Spectrometry of Water, Kluwer Academic Publisher, Netherlands

DigitalGlobe 2009, WorldView-2, viewed 10 July 2011, < 2http://worldview2.digitalglobe.com/about/>

Dustan, P, Dobson, E, Nelson, G 2001, Landsat thematic mapper: Detection of shifts in community composition of coral reefs, Conserv Biol 15: 892-902

Eakin, CM, Nim, C, Brainard, RE, Aubrecht, C, Elvidge, C, Gledhill, DK, Muller-Karger, F, Mumby, PJ, Skirving,W J, Strong, A E, Wang, M, Weeks, S \& Wentz, F 2010, Monitoring coral reefs from space. Oceanography (in press)

Eghtesadi-Araghi, P 2011, Coral reefs in the Persian Gulf and Oman Sea: An integrated perspective on some important stressors, Journal of Fishiers and Aquatic Science, vol. 6 no. 1, pp. $48-56$

ESRI 2011, ArcGIS Online: Bing Maps, viewed 16 July 2011, $<\mathrm{http} / /$ www.esri.com/software/arcgis/arcgisonline/bingmaps.html>

Fonseca, A, Guzmán, H, Cortés, J \& Soto, C 2010, Marine habitats map of "Isla del Caño", Costa Rica,comparing Quickbird and Hymap images classification results, Revista de Biologia Tropical, vol. 58, no. 1, pp. 373

GeoEye, 2011, Imagery Sources: IKONOS Setting the Standard, viewed 9 July 2011, $<$ http://www.geoeye.com/CorpSite/products-andservices/imagery-sources/> 
Hanaizumi, H, Akiba, M, Yamano, H \& Matsunaga, T 2008, A pan-sharpening method for satellite image-based coral reef monitoring with higher accuracy, Proceedings of the 11th International Coral Reef Symposium, Ft. Lauderdale, Florida, 7-11 July 2008, vol. 1, pp. 633-637 (Session number 17)

Hochberg, E, Andrefouet, S \& Tyler, M 2003, Sea surface correction of high spatial resolution Ikonos images to improve bottom mapping in nearshore environments, IEEE Trans on Geosci and Rem Sens, vol. 41, no. 7, pp. 1724-1729

Holden, H \& LeDrew, E 1998, The scientific issues surrounding remote detection of submerged coral ecosystems, Progress in Physical Geographyvol. 22, no. 2, pp. 190-221

Johannes, R E \& Riepen, M 1995, Environmental, economic and social implications of the live reef fish trade in Asia and the western Pacific, Report to the Nature Conservancy and the South Pacific Forum Fisheries Agency, pp. 80.

Kerr, J 2010, Worldview 2 offer new capabilities for monitoring of threatened coral reefs, Nova Southeastern University, National Coral Reef Institute

Kutser, T, Miller, I, \& Jupp, D L B 2006, Mapping coral reef benthic substrates using hyperspectral space-borne images and spectral libraries. Estuarine, Coastal and Shelf Science, vol. 70, pp. $449-460$

Knowlton, N \& Jackson, B C J 2008, Shifting Baseline, Local Impacts, and Global Change on Coral Reefs, PLOS Biology, vol. 6 , no. 2

Kuwait Diving Team (KDT) 2009, Kuwait Diving Team's Report of Coral Bleaching in the Reefs of the State of Kuwait, viewed 25 June 2011, < http://coralwatch.org/c/document_library/get_file?uuid $=0786$ 36be-d7f6-4c15-9cd8-dda01d201253\&groupId $=10136>$

Lee, Z, Carder, K, Mobley, C, Steward, R \& Patch, J 1999, Hyperspectral remote sensing for shallow waters: 2. Deriving bottom depths and water properties by optimization, Applied Optics, Vol.38, No. 18, Optical Society of America

Ling, Y., M. Ehlers, et al 2008, Effects of spatial resolution ratio in image fusion, International Journal of Remote Sensing, Vol.29, No.7, pp. 2157-2167

Lyzenga, R D 1978, Passive remote sensing techniques for mapping water depth and bottom features, Applied Optics, vol. 17, No. 3, Optical Society of America

Maeder, J, Narumalani, S, Rundquist, D, Perk, R, Schalles, J, Hutchins, K \& Keck, J 2002, Classifying and Mapping General Coral-Reef Structure Using Ikonos Data, Photogrammetric Engineering \& Remote Sensing, vol. 68, no. 12, pp. 1297-1305

Mitchell, H 2010, Image Fusion: Theories, Techniques and Application, Springer-Verlag Berlin Heidelberg

Moberg, F \& Folke, C 1999, Ecological Goods and Services of Coral Reef Ecosystems, Ecological Economics, vol. 29, no. 2, pp. 215-233

Mumby, P J \& Edwards, A J 2002, Mapping marine environments with IKONOS imagery: Enhanced spatial resolution can deliver greater thematic accuracy. Remote Sensing of Environment, vol. 82, pp. 248-257

Mumby, P, Green, E, Edwards, A \& Clark, C 1999, The costeffectiveness of remote sensing for tropical coastal resources assessment and management, Journal of Environmental Management, vol. 55, pp. 157-166
Mumby, P, Clark, C, Green, E \& Edwards, A 1998, The practical benefits of water column correction and contextual editing for mapping coral reefs, International Journal of Remote Sensing, vol. 19 , no. 1 , pp. 203-210

Mumby, P, Green, E, Edwards, A \& Clark, C 1997, Coral reef habitat mapping: how much detail can remote sensing provide?, Marine Biology, Vol. 130, no. 2, pp. 193-202

NASA 2011a, Remote sensing of coral reefs: Overview of integrated collaborations, projects and products, viewed 24 June 2011, <http://jsc.nasa.gov/reefs/>

NASA 2011b, Aqua Project Science, viewed 11 July 2011,<http://aqua.nasa.gov/about/instrument_modis.php>

NASA n.d, Quicklook: Landsat 4, 5, viewed 9 July 2011, $<\mathrm{http}: / /$ space.jpl.nasa.gov/msl/quicklooks/landsat4ql.html>

NASA 1999, Landsat 7: Supplying data users worldwide with low cost, multi-purpose, land remote sensing data into the next century, viewed 9 July 2011, <7http://geo.arc.nasa.gov/sge/landsat/17.html>

Nurlidiasari, M 2004, The Application of QuickBird and Multitemporal Landsat TM Data for Coral Reef Habitat Mapping; Case study: Derawan Island, East Kalimantan Indonesia, International Institute for Geo-Information Science and Earth Observation, Enschede, The Netherlands

Palandro, D, Andréfouët, S, Dustan, P \& Muller-Karger F 2003, Change detection in coral reef communities using Ikonos satellite imagery and historic aerial photographs, Int J Remote Sens, vol. 24, pp. 873-878

Peng, Y, Wang, J, Wang, C 2010, Polygonal Objects Fusion in Spatial Databases, International Conference on Electrical and Control Engineering, IEEE

Porter, J W \& Tougas, J I 2001, Reef ecosystems: Threats to their biodiversity, in Encyclopedia of Biodiversity, S.A.Levin, ed., Academic Press, San Diego, CA, pp. 73-95

Satellite Imaging Corporation (SIC), 2010, SPOT-5 Satellite Imagery and Sensor Characteristics, viewed 11 July 2011, <5http://www.satimagingcorp.com/satellitesensors/spot-5.html >

Scopélitis, J, Andréfouët, S, Phinn, S, Arroyo, L, Dalleau, M, Cros , A, Chabanet, P 2010, The next step in shallow coral reef monitoring: Combining remote sensing and in situ approaches, Marine Pollution Bulletin, vol. 60, pp. 19561968

Sterckx, S, Debruyn, W, Van Der Straete, T, Goossens, R \& Van Der Heijden, P 2005, Hyperspectral data for coral reef monitoring, A case study: Fordate, Tanimbar, Indonesia. In EARSeL eProceedings, vol. 4, pp. 18-25, viewed 19 July 2011: <las.physik.unioldenburg.de/eProceedings/>

USGS 2010, Sensors - Hyperion, viewed 15 July 2011, $<$ http://edcsns17.cr.usgs.gov/eo1/sensors/hyperion> 


\section{APPENDIX.1}

\section{Structure of Proposed Research}

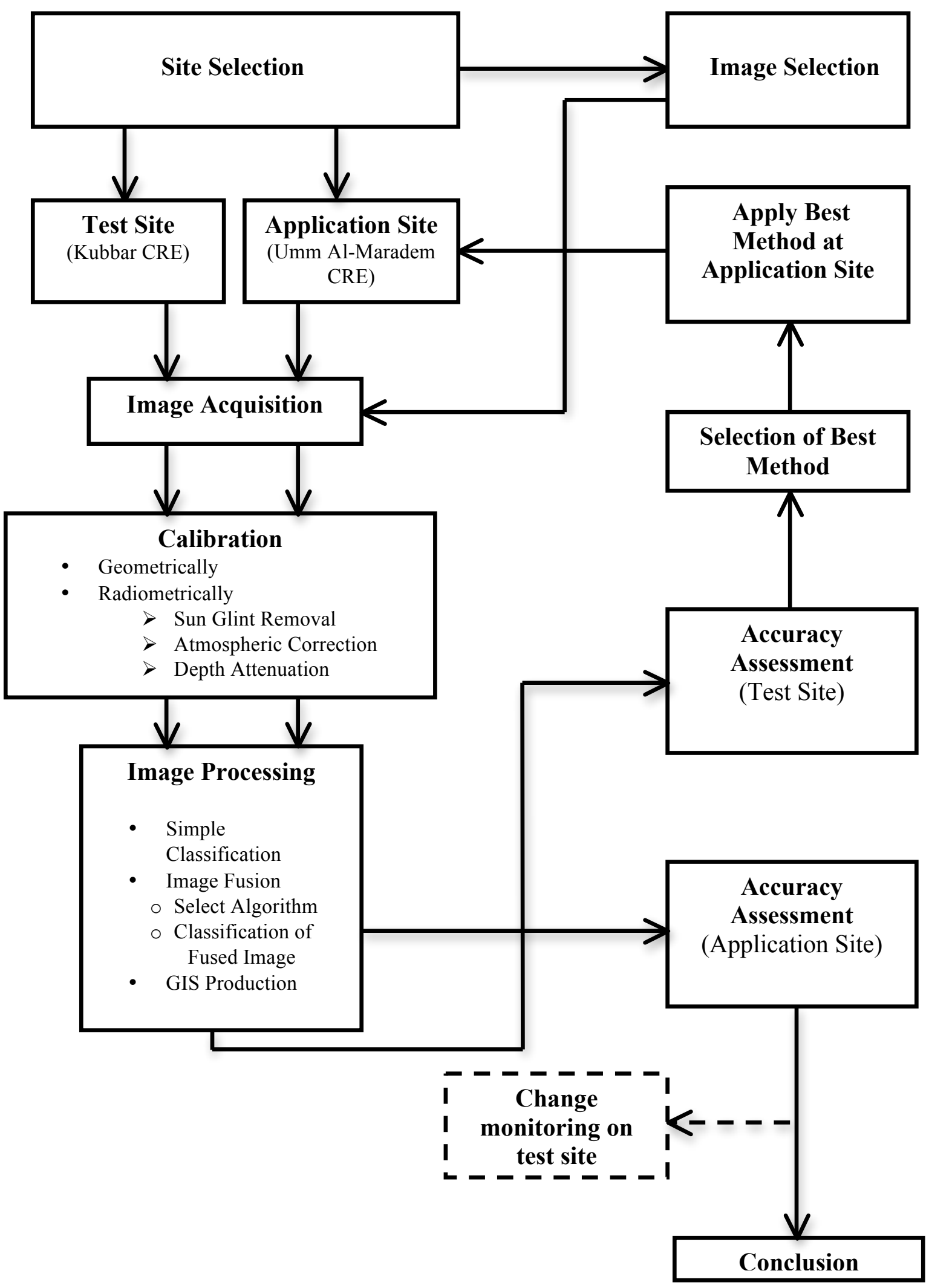

